\title{
Inhibition of transforming growth factor- $\beta$ release from tumor cells reduces their motility associated with epithelial-mesenchymal transition
}

\author{
YASUHIKO OHSHIO $^{1}$, KOJI TERAMOTO ${ }^{1}$, MASAYUKI HASHIMOTO ${ }^{1}$, SHOJI KITAMURA ${ }^{1}$, \\ JUN HANAOKA $^{1}$ and KEIICHI KONTANI ${ }^{2}$ \\ ${ }^{1}$ Department of Surgery, Shiga University of Medical Science, Otsu, Shiga 520-2192; ${ }^{2}$ Department of Respiratory, \\ Breast and Endocrine Surgery, Kagawa University Faculty of Medicine, Kita-gun, Kagawa 561-0793, Japan
}

Received February 6, 2013; Accepted April 25, 2013

DOI: 10.3892/or.2013.2505

\begin{abstract}
The high level of transforming growth factor- $\beta$ (TGF- $\beta$ ) in tumor tissue, which is primarily released from tumor cells, helps maintain their metastatic nature and exacerbates the creation of a pro-tumor microenvironment. Although the strategy of targeting TGF- $\beta$ in cancer therapy has shown promise, its effects remain limited. In the present study, we focused on tumor cells as sources of TGF- $\beta$ release, and hypothesized that inhibition of their TGF- $\beta$ release could suppress their epithelial-mesenchymal transition (EMT)associated metastatic nature and inactivate the induction of suppressor immune cells. To investigate this hypothesis, LLC1 cells, a mouse lung cancer cell line, were cultured with the TGF- $\beta$ release inhibitor tranilast and the motility of LLC1 cells was examined. Furthermore, to examine whether inhibition of TGF- $\beta$ release influences the induction of regulatory T (Treg) cells, spleen cells from normal mice were cultured in medium in which LLC1 cells had been cultured with tranilast. The results showed that tranilast inhibited the release of TGF- $\beta 1$ from LLC1 cells without affecting their proliferation. Inhibition of TGF- $\beta 1$ release suppressed the invasive activity of LLC1 cells, but enhanced their activity to adhere. mRNA levels of Slug and Twist were decreased in LLC1 cells, whereas levels of E-cadherin were recovered. Treg cells were less frequently induced by medium in which LLC1 cells had been cultured with tranilast. Taken together, inhibition of TGF- $\beta 1$ release dampens the metastatic nature of LLC1 cells through the downregulation of EMT and possesses the possibility to improve antitumor immune responses through suppression of Treg cell induction. These findings provide a new rationale for
\end{abstract}

Correspondence to: Dr Koji Teramoto, Department of Surgery, Shiga University of Medical Science, Seta-Tsukinowa, Otsu, Shiga 520-2192, Japan

E-mail: teramoto@belle.shiga-med.ac.jp

Key words: transforming growth factor- $\beta$, epithelial-mesenchymal transition, adhesive activity, invasive activity, regulatory $\mathrm{T}$ cells, tranilast development of TGF- $\beta$-targeted molecular immunotherapy against cancer.

\section{Introduction}

Transforming growth factor- $\beta$ (TGF- $\beta$ ) is a pleiotropic cytokine that has been implicated in wound healing, angiogenesis and regulation of immune systems. In the field of tumor biology, TGF- $\beta$ can act as both a promoter and a suppressor of tumor progression. In a xenograft model of breast cancer, endogenous TGF- $\beta$ reduced the size of the putative cancer stem or early progenitor cell population, and promoted differentiation of a progenitor cell population to an intrinsically less proliferative state (1). Another study in mice demonstrated that the genetic deletion of TGF- $\beta$ type II receptor in mammary epithelium enhanced tumor formation and metastases induced by polyomavirus middle T-antigen (2). These reports support the function of TGF- $\beta$ as a suppressor of tumor progression.

However, many reports underline the tumor-promoting effect of TGF- $\beta$. As tumors grow, tumor cells alter or lose TGF- $\beta$ signaling through the genetic deletion of signaling components including Smad 4 (3), becoming refractory for TGF- $\beta$-mediated growth inhibition of tumors. In breast and prostate cancer cells, stimulation of the phosphoinositide-3 kinase/protein kinase $\mathrm{B} /$ nuclear factor- $\kappa \mathrm{B}$ pathway with TGF- $\beta$ promotes the survival of tumor cells (4).

Regarding the contribution of TGF- $\beta$ to the motility of tumor cells, TGF- $\beta$ plays critical roles in their epithelial-mesenchymal transition (EMT), which is a key step in metastases to distant organs. During the process of EMT, TGF- $\beta$ promotes the expression of transcription factors such as Snail, Slug, Twist and Zeb1, leading to suppression of E-cadherin expression in the tumor cells (5). Given that E-cadherin is a primary epithelial cell-cell adhesion molecule (6), downregulation of E-cadherin promotes tumor cell migration and metastasis.

TGF- $\beta$ also contributes to tumor progression by suppression of antitumor immune responses. TGF- $\beta$ dampens the function of effector immune cell types including helper $T$ cells, cytotoxic T lymphocytes, natural killer cells and B cells, and activates regulatory $\mathrm{T}$ (Treg) cells, which suppress antitumor 
immune responses $(7,8)$. These immunosuppressive functions of TGF- $\beta$ decrease the efficacy of cancer immunotherapy.

As TGF- $\beta$ performs multiple functions in tumor progression, targeting TGF- $\beta$ is considered a promising strategy for the development of anticancer therapy. However, systemic inhibition of TGF- $\beta$ functions may also lead to undesirable adverse events. Transgenic mice expressing a soluble TGF- $\beta$ type II receptor exhibited an induced inflammatory response, including lymphocytic infiltration of the lungs, kidneys and pancreas (9). Other reports demonstrated that a TGF- $\beta$ type I receptor inhibitor administered orally induced physeal dysplasia in rats (10) and administration of a high dose of a TGF- $\beta$-neutralizing antibody induced epithelial hyperplasia of the tongue in a mouse model of familial adenomatous polyposis (11). To avoid adverse events induced by a TGF- $\beta$ inhibitor, local but not systemic inhibition of TGF- $\beta$ should be considered. We previously reported that local inhibition of TGF- $\beta$ in tumor-draining lymph nodes contributes to the induction of potent systemic antitumor immune responses with few adverse effects (12). In the report, we confirmed that local inhibition of TGF- $\beta$ was of value for the development of TGF- $\beta$-targeted strategies against cancers.

Based on the result that the main source of TGF- $\beta$ in a tumor-bearing host is tumor cells, we hypothesized that inhibition of TGF- $\beta$ release from tumor cells could provide an avenue for influencing tumor progression via TGF- $\beta$. To investigate this hypothesis, we applied tranilast as an inhibitor of TGF- $\beta$ release from tumor cells. Tranilast is an anti-allergic agent that has been used clinically in Japan, and is reported to inhibit the release of TGF- $\beta$ from immune cells (13).

In the present study, we evaluated the effect of tranilast as an inhibitor of TGF- $\beta$ release from tumor cells, and examined whether local inhibition of TGF- $\beta$ release by tranilast could suppress EMT-associated motility of tumor cells. Here, we report that the reduction of TGF- $\beta$ release from tumor cells by tranilast suppresses their EMT-associated capacities for metastasis and invasiveness, and contributes to a decrease in induction of Treg cells.

\section{Materials and methods}

Cells and reagents. The mouse Lewis lung carcinoma cell line LLC1 was provided by the Cell Resource Center for Biomedical Research, Tohoku University, Sendai, Japan. The cells were grown in Dulbecco's modified Eagle's medium (DMEM) (Nacalai Tesque, Inc., Kyoto, Japan) supplemented with $10 \%$ fetal calf serum, $100 \mathrm{U} / \mathrm{ml}$ penicillin $\mathrm{G}$, and $0.1 \mathrm{mg} / \mathrm{ml}$ streptomycin. Tranilast (N-[3,4-dimethoxycinnamoyl]-anthranilic acid) was kindly provided by Kissei Pharmaceutical Co., Ltd. (Matsumoto, Japan) and dissolved in dimethyl sulfoxide.

Reverse transcription-polymerase chain reaction (RT-PCR). Total RNA was extracted from LLC1 cells using the RNeasy Mini kit (Qiagen, Hilden, Germany) and was subjected to the reverse transcription reaction using the Cloned AMV First-Strand cDNA Synthesis kit (Life Technologies, Carlsbad, CA, USA). Each cDNA was amplified with specific paired primers as follows: TGF- $\beta$ forward, 5'-CTCCCGTGG CTTCTAGTGC-3' and reverse, 5'-GCCTTAGTTTGGACA GGATCTG-3'; Snail forward, 5'-GGAAGCCCAACTATA
GCGAGC-3' and reverse, 5'-CAGTTGAAGATCTTCCGC GAC-3'; Slug forward, 5'-CTCACCTCGGGAGCATAC AGC-3' and reverse, 5'-TGAAGTGTCAGAGGAAGGC GGG-3'; Twist forward, 5'-CGGGTCATGGCTAACGTG-3' and reverse, 5'-CAGCTTGCCATCTTGGAGTC-3'; vimentin forward, 5'-CACCCTGCAGTC ATTCAGACA-3' and reverse, 5'-GATTCCACTTTCCGTTCAAGGT-3'; E-cadherin forward, 5'-CAGGTCTCCTCATGGCTTTGC-3' and reverse, 5'-CTTCCGAAAAGAAGGCTGTCC-3'; $\beta$-actin forward, 5'-GCCCAGAGCAAGAGAGGTAT-3' and reverse, 5'-GGC CATCTCCTGCTCGAAGT-3'.

Quantification of protein levels of TGF- $\beta 1$. LLC1 cells were cultured in medium containing tranilast for 2 days, and the cells and the culture supernatant were harvested. Cytoplasmic protein of LLC1 cells was extracted using NE-PER Nuclear and Cytoplasmic Extraction Reagents (Thermo Fisher Scientific, Inc., Waltham, MA, USA). The levels of TGF- $\beta 1$ in the cytoplasmic protein of LLC1 and the culture supernatant were measured using the TGF- $\beta 1$ Quantikine ELISA kit (R\&D Systems, Inc., Minneapolis, MN, USA), according to the manufacturer's instructions.

Assays for cell proliferation and motility. LLC1 cells $\left(1 \times 10^{4}\right.$ cells/well) were cultured in 96-well plates with medium containing tranilast for 2 days, and CellTiter 96 AQueous One Solution Reagent (Promega, Madison, WI, USA) was added to each well. After additional culture for $4 \mathrm{~h}$, the absorbance was measured at $492 \mathrm{~nm}$.

To evaluate the invasive activity of LLC1, the cells were cultured in medium containing tranilast for 2 days. Subsequently, $4 \times 10^{4}$ cells/well were cultured for $22 \mathrm{~h}$ in $5 \%$ bovine serum albumin-DMEM containing tranilast in the upper compartment of a Transwell chamber with a Matrigelcoated membrane (pore size, $8 \mu \mathrm{m}$; BD Biosciences, San Jose, CA, USA) using 24-well plates. After scraping cells for removal on the surface using cotton swabs, the membrane was treated with fixation/staining solution containing $0.5 \%$ crystal violet, $12 \%$ formaldehyde and $10 \%$ ethanol as described elsewhere (14), and the invaded cells were counted under a microscope.

To evaluated the adhesive activity of LLC1, the cells were cultured in medium containing tranilast for 2 days. Subsequently, $4 \times 10^{4}$ cells/well were cultured in fibronectin-coated 96-well plates (BD Biosciences) for $2 \mathrm{~h}$. After vigorous vortexing, the nonadherent cells were discarded and treated with a fixation/staining solution. After washing in water and then drying, $1 \%$ SDS solution was added, and the extract absorbance was measured at $570 \mathrm{~nm}$.

Detection of Treg cells. Spleen cells from normal mice were cultured in medium in which LLC1 cells had been cultured with tranilast. Two days later, the cells were stained with anti-CD4, anti-CD25 and anti-FoxP3 antibodies (eBioscience, Inc., San Diego, CA, USA) according to the manufacturer's instructions, and analyzed on a FACScan flow cytometer (Becton Dickinson Immunocytometry System, Mountain View, CA, USA). Data are presented as dot blots produced using CellQuest software (Becton Dickinson Immunocytometry System). 
A

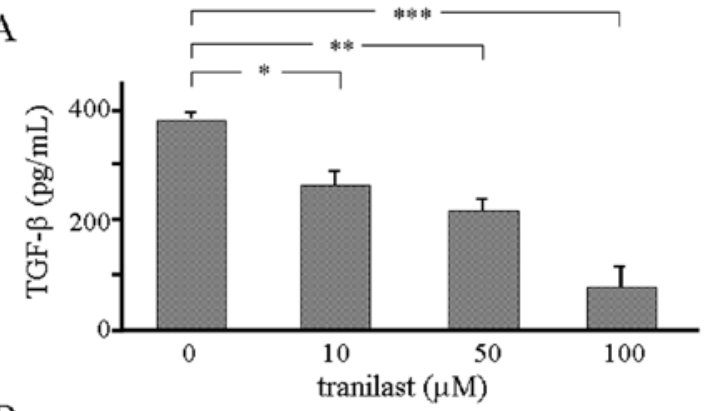

B

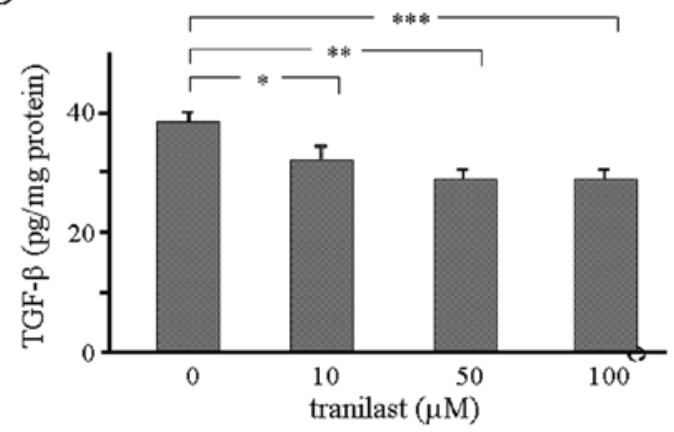

$\mathrm{C}$

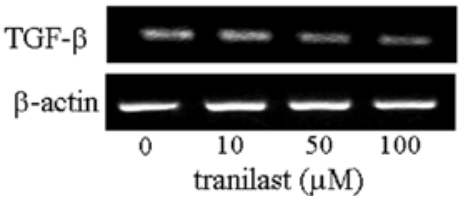

Figure 1 . Inhibitory effects of tranilast on transforming growth factor- $\beta$ (TGF- $\beta$ ) release and expression in LLC1 cells. LLC1 cells were cultured in medium containing tranilast. (A) TGF- $\beta$ release from LLC1 cells was decreased by incorporation of tranilast in a dose-dependent manner. ${ }^{*} \mathrm{P}=0.015,{ }^{* *} \mathrm{P}=0.005,{ }^{* * *} \mathrm{P}=0.004$. (B) The level of cytoplasmic TGF- $\beta$ in LLC1 cells was decreased by incorporation of tranilast. ${ }^{*} \mathrm{P}=0.024,{ }^{* *} \mathrm{P}=0.001$, ${ }^{*} *{ }^{* *} \mathrm{P}=0.001$. (C) The mRNA level of TGF- $\beta$ was downregulated by the incorporation of tranilast at a dose of $100 \mu \mathrm{M}$ in the culture medium.

Statistical analysis. The statistical significance of differential findings between groups was determined by the Student's t-test. P-values $<0.05$ were considered to indicate a statistically significant result. Representative results from three independent experiments with similar results are shown.

\section{Results}

Inhibition of TGF- $\beta 1$ release from LLC1 cells by tranilast. In the present study, we applied tranilast to inhibit the release of TGF- $\beta$ from tumor cells. Tranilast has been reported to inhibit the release of TGF- $\beta$ from immune cells; however, its effects on LLC1 cells remain undefined. First, we examined whether the release of TGF- $\beta$ from LLC1 cells would be inhibited by tranilast in vitro. LLC1 cells were cultured in medium containing tranilast for 2 days, and subsequently the level of TGF- $\beta 1$ in the culture medium was measured by ELISA. The level of TGF- $\beta 1$ was significantly decreased by incorporation of tranilast into the culture medium in a dose-dependent manner (Fig. 1A). We confirmed that tranilast inhibited the release of TGF- $\beta 1$ from $\mathrm{LLC1}$ cells, even following the incorporation of a low dose into the culture medium.

Next, we examined whether tranilast affects the expression of TGF- $\beta 1$ in LLC1 cells. The cells were cultured in medium

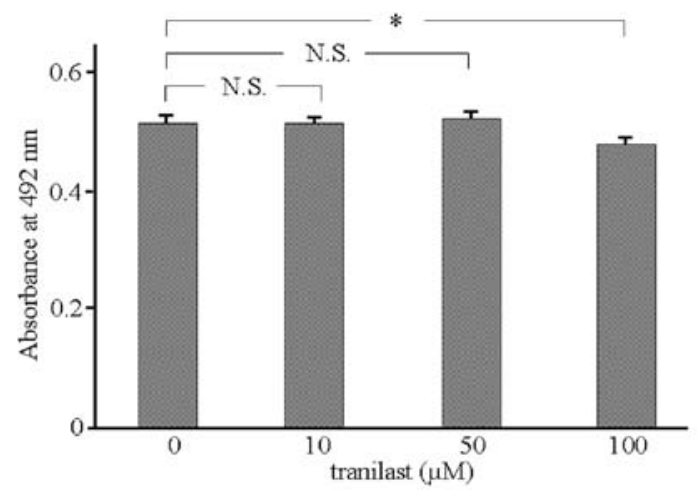

Figure 2. Effect of inhibition of TGF- $\beta$ release on the proliferative activity of LLC1 cells. LLC1 cells were cultured in medium containing tranilast. The proliferation of LLC1 cells was not noticeably suppressed by tranilast at doses ranging from 0 to $100 \mu \mathrm{M}$. ${ }^{*} \mathrm{P}=0.008$. N.S., no significant difference.

containing tranilast for 5 days, and the level of cytoplasmic TGF- $\beta 1$ was measured by ELISA. The data revealed that the level of cytoplasmic TGF- $\beta 1$ was significantly decreased by incorporation of tranilast (Fig. 1B). The level of TGF- $\beta 1$ mRNA in the cells was also evaluated, demonstrating that it was downregulated by incorporation of tranilast into the culture medium at a dosage of $100 \mu \mathrm{M}$ (Fig. 1C). These data indicate that the effects of tranilast on TGF- $\beta$ expression in LLC1 cells are variable and dose-dependent.

Inhibition of TGF- $\beta 1$ release has a minimal effect on the proliferative activity of $\mathrm{LLCl}$ cells. It has been reported that tranilast suppresses the proliferative activity of tumor cells while having few cytotoxic or apoptotic effects. We examined the effect of tranilast on the proliferative activity of LLC1 cells. The data showed that the proliferation of LLC1 cells was not suppressed markedly by tranilast at doses ranging from 0 to $100 \mu \mathrm{M}$ (Fig. 2). At this setting, tranilast inhibits the release of TGF- $\beta 1$ from LLC1 cells, without affecting the proliferative activity of the cells. The findings suggest that a large dose of tranilast would be required to suppress the proliferation of LLC1 cells, due to the aggressive nature of their progression. In this study, we focused on the suppressive effect of tranilast on TGF- $\beta 1$ release but not on the proliferation of LLC1 cells, and conducted subsequent experiments using doses of tranilast ranging from 0 to $100 \mu \mathrm{M}$.

EMT-associated motility of LLC1 cells is influenced by inhibition of TGF- $\beta 1$ release. We explored the impact of the inhibition of TGF- $\beta 1$ release from LLC1 cells on cell motility. In order to evaluate the influence on the invasive activity by inhibition of TGF- $\beta 1$ release, we cultured LLC1 cells in a Transwell chamber in medium containing tranilast. Two days later, the cells that had invaded through the Transwell membrane were counted. As shown in Fig. 3A, invasion of LLC1 cells was significantly decreased by the incorporation of tranilast into the culture medium, demonstrating that the invasive activity of LLC1 cells was suppressed by inhibition of TGF- $\beta 1$ release from the cells themselves.

Next, we examined whether inhibition of TGF- $\beta 1$ release from the cells affects the adhesive activity of LLC1 cells. For this purpose, LLC1 cells were cultured in fibronectin-coated 
A
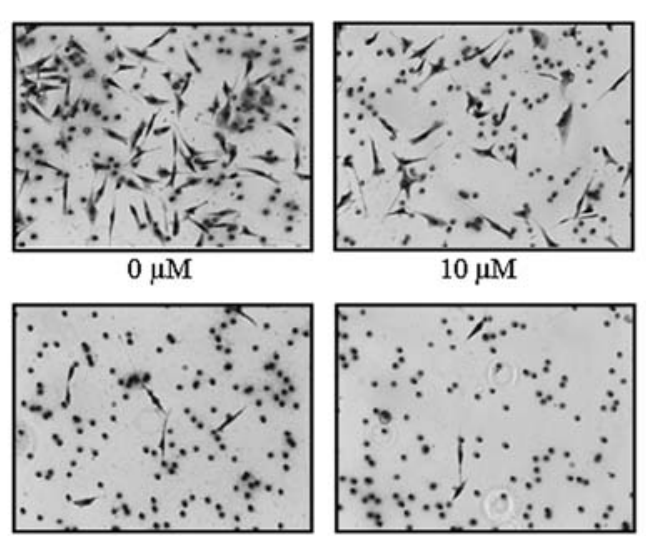

$50 \mu \mathrm{M}$

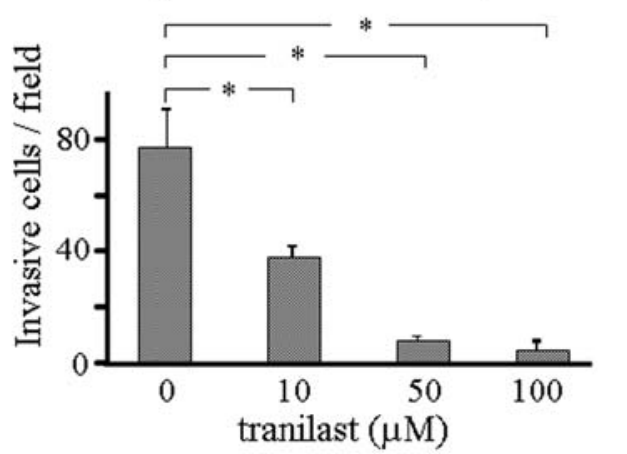

B

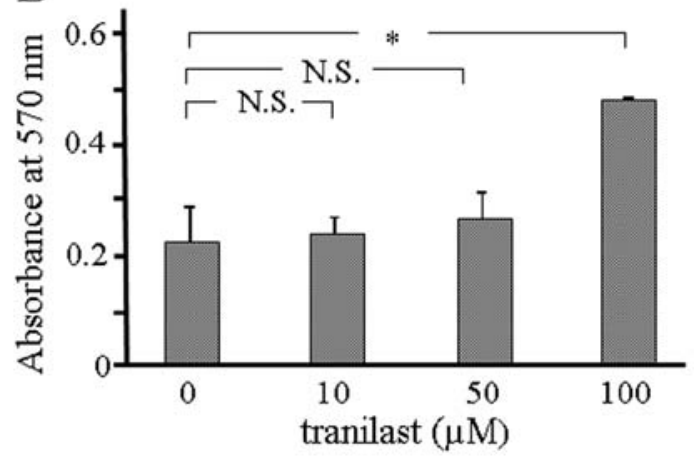

$\mathrm{C}$ Snail
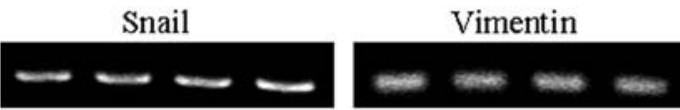

Slug

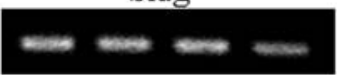

E-cadherin

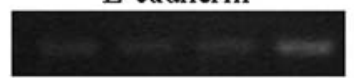

Twist

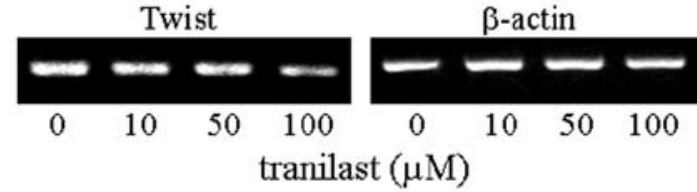

Figure 3. Epithelial-mesenchymal transition (EMT)-associated motility of LLC1 cells is influenced by the inhibition of transforming growth factor- $\beta$ (TGF- $\beta$ ) release. LLC1 cells were cultured in medium containing tranilast. (A) Invasive activity of LLC1 cells was significantly suppressed by the inhibition of TGF- $\beta$ released from the cell themselves. ${ }^{*} \mathrm{P}<0.001$. (B) The adhesive activity of LLC1 cells was improved by incorporation of tranilast at a dose of $100 \mu \mathrm{M}$ in the culture medium. " $\mathrm{P}=0.011$. N.S, no significant difference. (C) The expression of EMT-associated markers as measured by RT-PCR. Expression of both Slug and Twist was suppressed and that of E-cadherin was upregulated by incorporation of tranilast.

plates in medium containing tranilast for two days. The number of adherent LLC1 cells was significantly increased by incorporation of tranilast at the dose of $100 \mu \mathrm{M}$ into the culture medium (Fig. 3B), while $10 \mu \mathrm{M}$ of tranilast in the culture medium did not affect the adherent LLC1 cell count. These findings demonstrate that the adhesive activity of LLC1 cells was decreased by the powerful inhibition of TGF- $\beta 1$ release from the cells themselves.

On the basis of our findings concerning LLC1 cell motility, we aimed to ascertain whether the expression of EMT-associated markers in LLC1 cells is influenced by inhibition of TGF- $\beta 1$ release from LLC1 cells, and we examined mRNA expression of EMT-associated markers in LLC1 cells cultured in medium containing tranilast. As shown in Fig. 3C, among the EMT-associated transcriptional factors examined, expression of both Slug and Twist was suppressed and that of E-cadherin was upregulated by incorporation of tranilast. These results suggest that increased expression of EMT-associated markers in LLC1 cells can be achieved by powerful inhibition of TGF- $\beta 1$ release from the cells themselves.

Reduction in Treg cell induction by inhibition of TGF- $\beta 1$ release from LLC1 cells. From the viewpoint of tumor immunology, in the tumor microenvironment, TGF- $\beta$ plays a crucial role in inducing Treg cells. We examined whether inhibition of TGF- $\beta 1$ release from LLC1 cells suppresses the induction of Treg cells. Spleen cells from normal mice were cultured in medium in which LLC1 cells had been cultured with tranilast. Flow cytometry showed that the population of $\mathrm{CD} 4{ }^{+} \mathrm{CD} 25^{+} \mathrm{Foxp} 3^{+}$cells was significantly decreased by incorporation of tranilast (Fig. 4). These results suggest that local inhibition of TGF- $\beta 1$ release from LLC1 contributes to a decrease in the induction of Treg cells.

\section{Discussion}

In the present study, we focused on the release of TGF- $\beta$ from tumor cells, and examined the effects of the inhibition of TGF- $\beta$ release on their aggressive nature and on the proliferation of Treg cells. Our data demonstrated that inhibition of TGF- $\beta 1$ release from tumor cells by tranilast suppresses their EMT-associated capacity for motility and contributes to a decrease in induction of Treg cells in vitro.

Given that tranilast functions to inhibit the release of TGF- $\beta$ from immune cells (13), we applied tranilast as a TGF- $\beta$ release inhibitor in this study. In clinics in Japan, tranilast is administered to patient as an anti-allergic agent at the dose of $300 \mathrm{mg} / \mathrm{day}$. At this dose of tranilast, Cmax in peripheral blood may be estimated to be $\sim 100 \mu \mathrm{M}$ in humans (15). On the basis of the data, we conducted an in vitro study in which the culture medium contained tranilast at concentrating ranging from 0 to $100 \mu \mathrm{M}$. In this setting, the proliferation of LLC1 cells was not affected by $0-50 \mu \mathrm{M}$ of tranilast in the culture medium, 


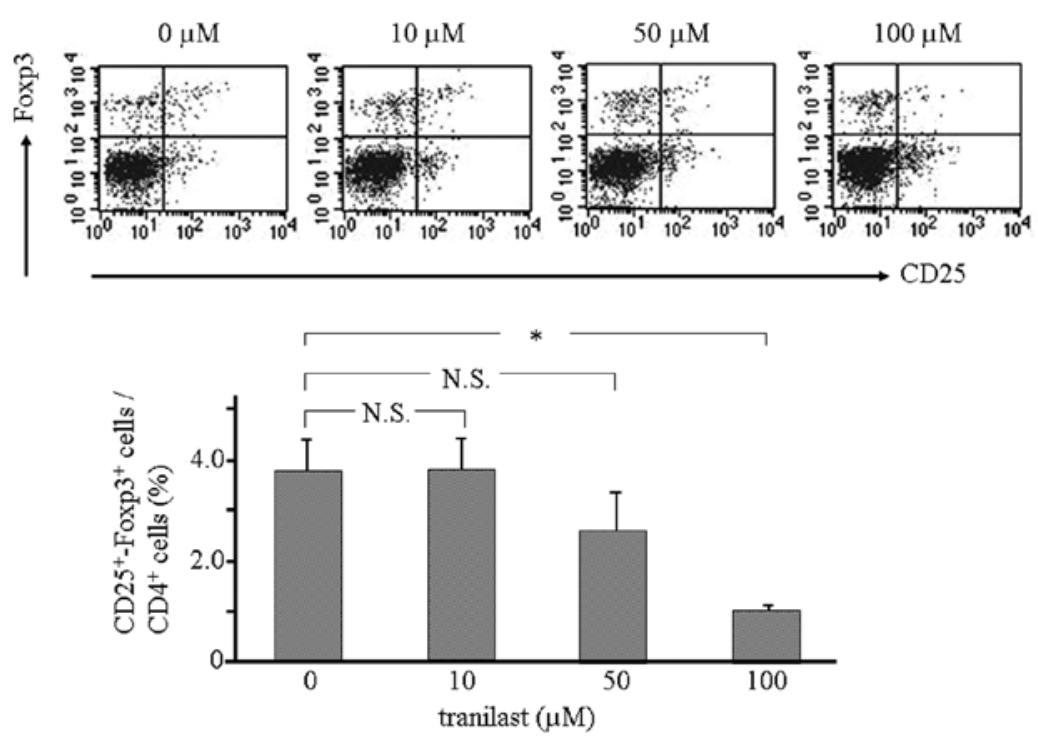

Figure 4. Reduction in Treg cell induction by inhibition of TGF- $\beta$ release from LLC1 cells. Spleen cells from normal mice were cultured in medium in which LLC1 cells had been cultured with tranilast. The population of $\mathrm{CD} 4{ }^{+} \mathrm{CD} 25^{+} \mathrm{Foxp} 3^{+}$cells was significantly decreased by incorporation of tranilast. ${ }^{*} \mathrm{P}=0.017$. N.S, no significant difference.

and even a dose of $100 \mu \mathrm{M}$ did not effectively suppress the proliferation of LLC1 cells.

These findings indicate that in this setting tranilast did not influence the cell cycle or apoptosis of LLC1 cells, nor did it confer cytotoxic activity against them. Tranilast has been reported to suppress the proliferation of other types of tumor cells such as pancreatic, prostate, breast, uterine leiomyoma and malignant glioma cells (16-20). The mechanisms underlying this suppressive effect are that tranilast arrests cell cycle progression through induction of the cyclin-dependent kinase (CDK) inhibitor. It was also reported that tranilast induced expression of p21 and p53 as well as G1 arrest, and decreased CDK2 activity in uterine leiomyoma cells (19) and in human malignant glioma cells (20). Izumi et al (17) reported that tranilast induced G1 arrest in prostate cancer cells via induction of p53, p21 and p27. Chakrabarti et al (21) reported that the proliferative response to tranilast differs between cell lines. In contrast with our study, higher doses of tranilast, $300 \mu \mathrm{M}$ or more, were applied in these previous studies. However, data from experiments employing a high dose of tranilast could not translate to cancer treatments in humans. A clinical study on the effect of tranilast on re-stenosis of the coronary artery after percutaneous transluminal coronary angioplasty demonstrated that the re-stenosis rate was significantly decreased by tranilast at a dose of $600 \mathrm{mg} /$ day. However, adverse events, including liver dysfunction and gastro-intestinal distress, also increased $\sim 2$-fold as compared with the control cohort (22). Based on this report, although high doses of tranilast can suppress the proliferation of tumor cells, they also cause intolerable adverse events in the human clinical setting.

As described above, tranilast is known to inhibit the release of TGF- $\beta$ from immune cells (13). It also has been reported that tranilast inhibits the release of TGF- $\beta 1$ and $-\beta 2$ from human malignant glioma cells (20). In the present study, we examined the effect of tranilast on the release of TGF- $\beta$ from mouse lung cancer cells, and confirmed that the level of TGF- $\beta 1$ in the culture medium was decreased in a dose-dependent manner by incorporation of tranilast. Even a low dose $(10 \mu \mathrm{M})$ of tranilast in the culture medium inhibited the release of TGF- $\beta 1$ from tumor cells effectively. Furthermore, we examined whether tranilast inhibits the expression of TGF- $\beta 1$ at the mRNA and cytoplasmic protein levels. Our results demonstrated that the expression of TGF- $\beta 1$ mRNA in LLC1 cells was not affected at lower doses of tranilast, and higher doses of tranilast were required to suppress the expression of TGF- $\beta 1 \mathrm{mRNA}$. Cytoplasmic levels of TGF- $\beta 1$ protein in LLC1 cells were decreased by low doses of tranilast. These data demonstrate that tranilast affects tumor cells, causing inhibition of TGF- $\beta 1$ release and suppression of the mRNA or protein level of TGF- $\beta 1$ expression, depending on the dose incorporated into the culture medium.

Apart from tranilast, other drugs have also been reported to possess an anti-TGF- $\beta$ effect. Angiotensin-converting enzyme (ACE) inhibitors and antagonists of the angiotensin II type 1 receptor (AT1), two commonly used anti-hypertensive drugs, also have an effect on inhibition of TGF- $\beta$. TGF- $\beta$ production of cardiac and renal cells was found to be decreased by the AT1 antagonist losartan through the downregulation of thrombospondin-1, which activates latent TGF- $\beta$ (23). Both ACE and AT1 inhibitors have been reported to have a suppressive effect on tumor cells; however, captopril, one of the ACE inhibitors, had no significant effect on expression of TGF- $\beta$ mRNA and protein in mouse renal cancer cells (24).

Although various cell types in tumor tissue release TGF- $\beta$, the primary source of TGF- $\beta$ may be tumor cells. The aggressiveness of tumor cells is determined by the levels of TGF- $\beta$, which are released by tumor cells themselves. High levels of TGF- $\beta$ in tumor cells modulate their metastatic motility. With this in mind, we focused on downregulation of TGF- $\beta$ levels in the tumor environment, and examined the effect of inhibition of TGF- $\beta$ release on the motility of tumor cells in vitro. In the setting of our study, incorporation of tranilast into the culture medium was able to create an environment where the level of TGF- $\beta 1$ was decreased through inhibition of TGF- $\beta 1$ release. 
Invasive activity of LLC1 cells was effectively suppressed by incorporation of even a low dose $(10 \mu \mathrm{M})$ of tranilast. However, a higher dose of tranilast $(100 \mu \mathrm{M})$ was required to affect the adhesive activity of LLC1 cells. Adhesive activity of tumor cells is associated with the expression of E-cadherin, which is an epithelial cell-cell adhesion molecule and a major component of epithelial adherens junction. TGF- $\beta$, as well as other growth factors including hepatocyte growth factor, insulin-like growth factor and fibroblast growth factor, is known to provoke the loss of E-cadherin function, leading to disruption of adhesive activity (25). However, the invasive activity of tumor cells is associated with integrins, which constitute a family of transmembrane receptors that bind to the extracellular matrix extracellularly and to the cytoskeleton intracellularly. TGF- $\beta$ induces the de novo expression of several types of integrins, such as $\alpha 5 \beta 1, \alpha v \beta 3, \alpha v \beta 5$ and $\alpha v \beta 6$, in epithelial cells (26). These integrins enhance the migratory and invasive activity of tumor cells. Although both invasive and adhesive activities are regulated by TGF- $\beta$, our data indicate that the invasive activity of LLC1 cells is more susceptible than its adhesive activity to the inhibition of the release of TGF- $\beta$. In turn, adhesive activity may be more dependent on TGF- $\beta$ than invasive activity.

The modulation of cell motility, called EMT, is the primary step when tumor cells metastasize to distant organs. The process of EMT, in which tumor cells modulate their invasive and adhesive activities, has been reported to be regulated by TGF- $\beta$ (6). The alteration of the cell motility observed in this study suggests that EMT of tumor cells may be suppressed by inhibition of TGF- $\beta$ release. When we examined the expression of transcription factors associated with EMT, expression of both Slug and Twist was suppressed, and that of E-cadherin was upregulated. These findings were observed at a higher $(100 \mu \mathrm{M})$ but not at a lower $(10 \mu \mathrm{M})$ dose of tranilast. These results can be explained by several factors. First, transcriptional changes in EMT of tumor cells may depend on the level of TGF- $\beta$ in the environment. Reduction in the TGF- $\beta 1$ level by a low dose $(10 \mu \mathrm{M})$ of tranilast may be insufficient to induce changes of EMT-associated transcription factors, and a much greater reduction in the TGF- $\beta$ level may be needed to do so. Second, on the basis of the result that a higher dose $(100 \mu \mathrm{M})$ of tranilast suppresses the mRNA expression of TGF- $\beta 1$ in LLC1 cells, downregulation of TGF- $\beta$ mRNA may be required to induce the alteration of EMT-associated transcription factors. It has been reported that EMT-associated transcription factors, such as Snail, Slug, Twist and Zeb1, that are upregulated by TGF- $\beta$ signaling, can affect the expression of E-cadherin directly or indirectly (5). Both Snail and Slug are direct inhibitors of E-cadherin, while Twist suppresses the expression of E-cadherin indirectly (6). Given that EMT-associated factors are under complex regulation, the effect of inhibition of TGF- $\beta$ release from tumor cells on their expression may depend on the degree of decrease in the level of TGF- $\beta$.

In the tumor microenvironment, the level of TGF- $\beta$ can induce Treg cells, contributing to suppression of antitumor immune responses in tumor-bearing hosts. Controlling the activity of Treg cells should be one of the strategies employed in cancer therapy. If the level of TGF- $\beta$ in the tumor tissue can be attenuated, the population of Treg cells induced will be decreased, contributing to improvement of antitumor immune responses. In this study, we examined whether inhibition of
TGF- $\beta$ release from tumor cells by tranilast suppresses the induction of Treg cells. Spleen cells from normal mice were cultured in medium in which LLC1 cells had been cultured with tranilast, where the level of TGF- $\beta 1$ had been reduced. In this setting, the population of Treg cells $\left(\mathrm{CD} 4^{+} \mathrm{CD} 25^{+} \mathrm{Foxp} 3^{+}\right.$ cells) induced was significantly decreased, depending on the level of TGF- $\beta 1$ in the culture medium. These data are consistent with previous reports that addition of a neutralizing antibody against TGF- $\beta$ into the culture supernatant of prostate tumor cells prevented $\mathrm{CD} 4^{+} \mathrm{CD} 25^{-} \mathrm{T}$ cells from expressing Foxp3 (27). Another report showed that the number of Treg cells infiltrating the tumor was decreased by TGF- $\beta$ siRNA in mice with colon cancer (28). Attenuation of TGF- $\beta$ levels in tumor tissue can decrease the distribution of Treg cells, and inhibition of TGF- $\beta$ release from tumor cells contributes to creating an environment where induction of Treg cells is suppressed.

In conclusion, inhibition of TGF- $\beta$ release from tumor cells by tranilast suppresses the EMT-associated metastatic and invasive capacities of tumor cells and contributes to a decrease in induction of Treg cells in vitro. These findings indicate that inhibition of TGF- $\beta$ release from tumor cells has the potential to suppress metastasis of tumor cells and improve systemic antitumor immune responses, providing a new rationale for the development of TGF- $\beta$-targeted molecular immunotherapy against cancer.

\section{References}

1. Tang B, Yoo N, Vu M, Mamura M, Nam JS, Ooshima A, Du Z, Desprez PY, Anver MR, Michalowska AM, Shih J, Parks WT and Wakefield LM: Transforming growth factor- $\beta$ can suppress tumorigenesis through effects on the putative cancer stem or early progenitor cell and committed progeny in a breast cancer xenograft model. Cancer Res 67: 8643-8652, 2007.

2. Forrester E, Chytil A, Bierie B, Aakre M, Gorska AE, Sharif-Afshar AR, Muller WJ and Moses HL: Effect of conditional knockout of the type II TGF- $\beta$ receptor gene in mammary epithelia on mammary gland development and polyomavirus middle $\mathrm{T}$ antigen induced tumor formation and metastasis. Cancer Res 65: 2296-2302, 2005.

3. Jakowlew SB: Transforming growth factor- $\beta$ in cancer and metastasis. Cancer Metastasis Rev 25: 435-457, 2006.

4. Galliher AJ, Neil JR and Schiemann WP: Role of transforming growth factor- $\beta$ in cancer progression. Future Oncol 2: 743-763, 2006.

5. Talbot LJ, Bhattacharya SD and Kuo PC: Epithelial-mesenchymal transition, the tumor microenvironment, and metastatic behavior of epithelial malignancies. Int J Biochem Mol Biol 3: 117-136, 2012.

6. Yang J and Weinberg RA: Epithelial-mesenchymal transition: at the crossroads of development and tumor metastasis. Dev Cell 14: 818-829, 2008

7. Letterio JJ and Roberts AB: Regulation of immune responses by TGF- $\beta$. Annu Rev Immunol 16: 137-161, 1998.

8. Wrzesinski SH, Wan YY and Flavell RA: Transforming growth factor-beta and the immune response: implications for anticancer therapy. Clin Cancer Res 13: 5262-5270, 2007.

9. Yang YA, Dukhanina O, Tang B, Mamura M, Letterio JJ, MacGregor J, Patel SC, Khozin S, Liu ZY, Green J, Anver MR, Merlino G and Wakefield LM: Lifetime exposure to a soluble TGF- $\beta$ antagonist protects mice against metastasis without adverse side effects. J Clin Invest 109: 1607-1615, 2002.

10. Frazier K, Thomas R, Scicchitano M, Mirabile R, Boyce R, Zimmerman D, Grygielko E, Nold J, DeGouville AC, Huet $S$, Laping N and Gellibert F: Inhibition of ALK5 signaling induces physeal dysplasia in rats. Toxicol Pathol 35: 284-295, 2007.

11. Prud'homme GJ: Pathobiology of transforming growth factor $\beta$ in cancer, fibrosis and immunologic disease, and therapeutic considerations. Lab Invest 87: 1077-1091, 2007. 
12. Fujita T, Teramoto K, Ozaki Y, Hanaoka J, Tezuka N, Itoh Y, Asai T, Fujino S, Kontani K and Ogasawara K: Inhibition of transforming growth factor- $\beta$-mediated immunosuppression in tumor-draining lymph nodes augments antitumor responses by various immunologic cell types. Cancer Res 69: 5142-5150, 2009.

13. Suzawa H, Kikuchi S, Ichikawa K and Koda A: Inhibitory action of tranilast, an anti-allergic drug, on the release of cytokines and $\mathrm{PGE}_{2}$ from human monocytes-macrophages. Jpn J Pharmacol 60: 85-90, 1992.

14. Kudo-Saito C, Shirako H, Takeuchi T and Kawakami Y: Cancer metastasis is accelerated through immunosuppression during Snail-induced EMT of cancer cells. Cancer Cell 15: 195-206, 2009.

15. Tanaka K, Honda M, Kuramochi T and Morioka S: Prominent inhibitory effects of tranilast on migration and proliferation and collagen synthesis by vascular smooth muscle cells. Atherosclerosis 107: 179-185, 1994.

16. Hiroi M, Onda M, Uchida E and Aimoto T: Anti-tumor effect of N-[3,4-dimethoxycinnamoyl]-anthranilic acid (tranilast) on experimental pancreatic cancer. J Nippon Med Sch 69: 224-234, 2002.

17. Izumi K, Mizokami A, Li YQ, Narimoto K, Sugimoto K, Kadono Y, Kitagawa Y, Konaka H, Koh E, Keller ET and Namiki M: Tranilast inhibits hormone refractory prostate cancer cell proliferation and suppresses transforming growth factor $\beta 1$-associated osteoblastic changes. Prostate 69: 1222-1234, 2009.

18. Subramaniam V, Chakrabarti R, Prud'homme GJ and Jothy S: Tranilast inhibits cell proliferation and migration and promotes apoptosis in murine breast cancer. Anticancer Drugs 21: 351-361, 2010.

19. Shime H, Kariya M, Orii A, Momma C, Kanamori T, Fukuhara K, Kusakari T, Tsuruta Y, Takakura K, Nikaido T and Fujii S: Tranilast inhibits the proliferation of uterine leiomyoma cells in vitro through G1 arrest associated with the induction of $\mathrm{p} 21^{\text {waf } 1}$ and p53. J Clin Endocrinol Metab 87: 5610-5617, 2002.
20. Platten M, Wild-Bode C, Wick W, Leitlein J, Dichgans J and Weller M: N-[3,4-dimethoxycinnamoyl]-anthranilic acid (tranilast) inhibits transforming growth factor- $\beta$ relesase and reduces migration and invasiveness of human malignant glioma cells. Int J Cancer 93: 53-61, 2001.

21. Chakrabarti R, Subramaniam V, Abdalla S, Jothy S and Prud'homme GJ: Tranilast inhibits the growth and metastasis of mammary carcinoma. Anticancer Drugs 20: 334-345, 2009.

22. Kato K, Tamai H, Hayakawa H, Yamaguchi T, Kanmatsuse K, Haze K, Aizawa T, Suzuki S, Takase S, Suzuki T, Nishikawa H, Nakanishi S, Kato O and Nakashima M: Clinical evaluation of tranilast on restenosis after percutaneous transluminal coronary angioplasty (PTCA) - a double blind placebo-controlled comparative study. J Clin Therapy Med 12: 65-85, 1996.

23. Zhou Y, Poczatek MH, Berecek KH and Murphy-Ullrich JE: Thrombospondin 1 mediates angiotensin II induction of TGF- $\beta$ activation by cardiac and renal cells under both high and low glucose conditions. Biochem Biophys Res Commun 339: 633-641, 2006

24. Miyajima A, Asano T and Hayakawa M: Captopril restores transforming growth factor- $\beta$ type II receptor and sensitivity to transforming growth factor- $\beta$ in murine renal cell cancer cells. J Urol 165: 616-620, 2001.

25. Yilmaz $M$ and Christofori G: Mechanisms of motility in metastasizing cells. Mol Cancer Res 8: 629-642, 2010.

26. Margadant $C$ and Sonnenberg A: Integrin-TGF- $\beta$ crosstalk in fibrosis, cancer and wound healing. EMBO Rep 11:97-105, 2010.

27. Liu VC, Wong LY, Jang T, Shah AH, Park I, Yang X, Zhang Q, Lonning S, Teicher BA and Lee C: Tumor evasion of the immune system by converting $\mathrm{CD} 4^{+} \mathrm{CD} 25^{-} \mathrm{T}$ cells into $\mathrm{CD} 4^{+} \mathrm{CD} 25^{+}$ T regulatory cells: role of tumor-derived TGF- $\beta$. J Immunol 178: 2883-2892, 2007.

28. Conroy H, Galvin KC, Higgins SC and Mills KH: Gene silencing of TGF- $\beta 1$ enhances antitumor immunity induced with a dendritic cell vaccine by reducing tumor-associated regulatory T cells. Cancer Immunol Immunother 61: 425-431, 2012. 